\title{
A INFLUENCIA DAS DIFERENTES TIPOLOGIAS DE FLORESTA URBANA NO MICROCLIMA DO ENTORNO IMEDIATO
}

\section{THE INFLUENCE OF THE DIFFERENT TYPES OF URBAN FOREST IN THE IMMEDIATE SURROUNDING MICROCLIMATE}

\author{
Angeline Martini ${ }^{1}$ Daniela Biondi ${ }^{2}$ Antonio Carlos Batista ${ }^{2}$
}

\begin{abstract}
RESUMO
A floresta urbana gera um microclima mais agradável para o ser humano, tanto no seu interior como nas áreas externas próximas. Assim, o objetivo desta pesquisa foi analisar a influência que as diferentes tipologias de floresta urbana exercem no seu entorno imediato, destacando quantitativamente as diferenças entre o microclima interno e externo a essas áreas. Para isso foram selecionadas diferentes formas de floresta urbana na cidade de Curitiba-PR: Remanescente Florestal, Área Verde Antiga, Área Verde Moderna, Arborização de Ruas e Árvore Isolada. A influência no entorno imediato foi analisada com o método de transectos móveis, percorrendo $500 \mathrm{~m}$ de distância de em uma rua adjacente à área selecionada, com coleta de dados a cada $50 \mathrm{~m}$. Os resultados indicam diferenças estatísticas significativas entre o microclima interno e externo às tipologias de floresta urbana. Ao longo do transecto percorrido, a temperatura foi em média $2,3{ }^{\circ} \mathrm{C}$ mais elevada do que no interior das tipologias de floresta urbana, a umidade relativa foi menor em 4,6 unidades e a velocidade do vento $0,2 \mathrm{~m} / \mathrm{s}$ maior. A maior diferença de temperatura e umidade relativa entre o ambiente interno e externo foi encontrada no Remanescente Florestal e a menor na Arborização de Ruas. Conclui-se que as diferentes tipologias de floresta urbana exercem influência significativa no microclima do entorno imediato.
\end{abstract}

Palavras-chave: transectos móveis; temperatura; arborização urbana; melhoria climática.

\begin{abstract}
The urban forest generates a microclimate more pleasant for the human being, in its interior as in the near external areas. Thus, the main goal of this research was to analyze the influence that the different typologies of urban forest exert in their immediate surrounding, highlighting quantitatively the differences between the internal and external microclimate to these areas. For this, areas of different types of urban forest were selected in the city of Curitiba-PR: Remaining Forest, Old Green Area, Modern Green Area, Street Trees and Isolated Tree. The influence in the immediate surrounding was analyzed with the mobile transect method, traveling $500 \mathrm{~m}$ away from a street adjacent to the selected area, with data collection every $50 \mathrm{~m}$. The results indicate statistical differences between the internal and external microclimate to the typologies of urban forest. During the transect, the temperature was on average $2.3^{\circ} \mathrm{C}$ higher than in the interior of the urban forest typologies, the relative humidity was lower in 4.6 units and the wind velocity $0.2 \mathrm{~m} / \mathrm{s}$ higher. The greatest difference in temperature and relative humidity between the internal and external environment was found in the Remaining Forest and the smallest in the Street Trees. It is concluded that the different typologies of urban forest exert a significant influence on the immediate surrounding microclimate.
\end{abstract}

Keywords: mobile transects; temperature; afforestation; climate improvement.

1 Engenheira Florestal, Dr ${ }^{\mathrm{a}}$., Professora Adjunta da Universidade Federal de Viçosa, Av. Purdue, s/n, Ed. Reinaldo de Jesus Araújo, Campus Universitário, CEP 36570-900, Viçosa (MG), Brasil. martini@ufv.br

2 Engenheiro(a) Florestal, Dr(a)., Professor(a) Titular da Universidade Federal do Paraná, Av. Pref. Lothário Meissner, 632, Jardim Botânico, CEP 80210-170, Curitiba (PR), Brasil. dbiondi@ufpr.br / batistaufpr@ufpr.br

Recebido para publicação em 20/02/2017 e aceito em 5/07/2017

Ci. Fl., v. 28, n. 3, jul. - set., 2018 


\section{INTRODUÇ̃̃O}

A presença do ecossistema natural, dentro dos limites das cidades, contribui para a saúde pública e aumenta a qualidade de vida dos cidadãos urbanos (ODUM, 2004). As reações benéficas desencadeadas pela exposição aos ambientes e elementos naturais são características adaptativas do passado, que tiveram origem na longa história evolutiva da espécie humana, sempre em contato com os ambientes naturais (JOYE; BERG, 2011). Deste modo, a simples presença de vegetação nas cidades já tem sido considerada um sinônimo de qualidade de vida (ALVAREZ, 2004).

A população das cidades em todo o mundo sofre com problemas de saúde causados por sobreaquecimento das áreas urbanas e há indícios de que esses problemas serão intensificados pela mudança do clima em escala global (BROWN et al., 2015). Por esse motivo, nas últimas décadas, sustentadas pela teoria científica e evidências empíricas, cidades de todo o mundo têm promovido florestas urbanas como uma forma de manter seus cidadãos saudáveis, bem como melhorar as condições ambientais e econômicas (JIANG et al., 2015).

Entende-se por floresta urbana toda cobertura vegetal situada dentro do perímetro urbano, podendo ser de domínio público ou particular e que se divide em áreas verdes e arborização de ruas (BIONDI, 2015). Compreende, portanto, as árvores plantadas em calçadas, parques, praças, jardins, quintais, estacionamentos, cemitérios e bosques urbanos, mesmo que estejam localizadas em áreas suburbanas e periurbanas (ARAÚJO; ARAÚJO, 2011).

Segundo Basso e Correa (2014), essa vegetação das cidades possibilita a criação de microclimas diferenciados devido ao sombreamento, da redução da velocidade dos ventos, da proteção solar ao ambiente edificado, da redução das temperaturas, da evapotranspiração e da retenção de umidade do solo e do ar. Também deve-se destacar que as folhas possuem baixo índice de reflexão, absorvendo a radiação solar incidente e bloqueando parte considerável da radiação solar direta (BASSO; CORREA, 2014), dependendo da densidade da folhagem, extensão e espessura da copa, podem interceptar grandes quantidades de radiação solar (BARBIRATO; TORRES; SOUZA, 2011). Consequentemente, a vegetação transforma a temperatura da superfície que interfere também na temperatura do ar (SHASHUA-BAR et al., 2010). Além disso, as árvores modificam uma pequena parte da radiação solar absorvida pela fotossíntese em calor latente (transpiração), o que evita a conversão em energia térmica (FRYD; PAULEIT; BUHLER, 2011; CHEN et al., 2014). Desta forma, as áreas vegetadas não se tornam tão quentes durante o dia como as superfícies construídas devido à transpiração das plantas (CHEN et al., 2014).

As áreas que apresentam vegetação no ambiente urbano podem proporcionar microclimas mais frios e criar ilhas de frescor urbanas (KONG et al., 2014), que atuam de modo importante para a saúde humana e sustentabilidade das cidades (CHEN et al., 2014). Esses ambientes urbanos capazes de gerar um resfriamento localizado, originando as ilhas de frescor urbano e se contrapõem ao efeito de ilhas de calor urbano, amplamente divulgado (SHASHUA-BAR; PEARLMUTTER; ERELL, 2009). Atuam assim, como uma estratégia de adaptação para lidar com as mudanças climáticas futuras, atenuando os efeitos das ilhas de calor (KONG et al., 2014).

Muitas pesquisas têm sido destinadas à avaliação da vegetação urbana, principalmente no contexto de sustentabilidade, aceleração da urbanização e qualidade de vida (RASKOVIC; DECKER, 2015). Kurbán et al. (2002), na cidade de San Juan (Argentina), demonstraram que o efeito da arborização resultou em uma diminuição de $2,1^{\circ} \mathrm{C}$ na temperatura e em um aumento de 5,2\% na umidade relativa. Em Freiburg (Alemanha), a diferença entre a área com árvores e sem árvores foi de $2,2^{\circ} \mathrm{C}$ para a temperatura e de 5 a $7 \%$ para a umidade relativa (STREILING; MATZARAKIS, 2003).

Em um parque de Nagoya (Japão), Hamada e Ohta (2010) encontraram diferenças de temperatura de $1,9^{\circ} \mathrm{C}$ no verão e $-0,3^{\circ} \mathrm{C}$ no inverno. Em Manchester (Inglaterra), na estação do verão, foi constatado que embora a sombra de uma árvore só reduza as temperaturas do ar em 1 ou $2^{\circ} \mathrm{C}$, em dias quentes e ensolarados as temperaturas percebidas são significativamente mais baixas na sombra (ARMSON; STRINGER; ENNOS, 2012).

Leal (2012), ao analisar o clima local da cidade de Curitiba, verificou que nas regiões com maior quantidade de áreas permeáveis, concentração de remanescentes florestais ou presença de áreas verdes públicas ocorreram menores temperaturas e aumento da umidade relativa do ar, atuando como "ilhas de 
frescor urbano". Também na cidade de Curitiba, Martini et al. (2011) verificaram que a temperatura de um fragmento florestal urbano foi $5^{\circ} \mathrm{C}$ menor, enquanto a umidade relativa foi maior em 27,6 unidades. Além disso, a temperatura do ar em uma rua arborizada foi em média $1,7^{\circ} \mathrm{C}$ menor do que na rua sem arborização e a umidade relativa, maior em 6,9 unidades (MARTINI, 2013).

Pode-se observar que a floresta urbana tem sido usada como uma medida para esfriar porções de áreas urbanas, reduzindo a intensidade e magnitude dos impactos negativos das ilhas de calor (CHANG; LI, 2014), mas para isso, são necessárias informações específicas e rigorosas a respeito do enfoque climatológico (CHANG; LI; CHANG, 2007). É preciso reforçar a necessidade de investigação nesta área, pois ainda não há plena consciência dos benefícios que as árvores podem trazer, embora um elevado número de investigações sobre o assunto já terem sido realizadas nas últimas décadas (DRAPER; RICHARDS, 2009).

Torna-se fundamental que estudos sejam desenvolvidos nas cidades para quantificar criteriosamente esta influência e indicar formas adequadas de planejar e implantar a floresta urbana de modo a proporcionar microclimas mais confortáveis termicamente, contemplando inclusive as diferentes tipologias desta floresta urbana. Desta forma, o objetivo desta pesquisa foi analisar a influência que as diferentes tipologias de floresta urbana exercem no seu entorno imediato, destacando quantitativamente as diferenças entre o microclima interno e externo a essas áreas.

\section{MATERIAL E MÉTODOS}

O estudo foi desenvolvido na cidade de Curitiba, localizada na região sul do Brasil a 934,6 m de altitude média. Com base na classificação de Köppen, o clima de Curitiba é do tipo $\mathrm{Cfb}$, subtropical úmido, mesotérmico, sem estação seca, com verões frescos e invernos com geadas frequentes e ocasional precipitação de neve (INSTITUTO DE PESQUISA E PLANEJAMENTO URBANO DE CURITIBA, 2011). O verão é ameno (com temperaturas médias de $\left.19,7^{\circ} \mathrm{C}\right)$ e o inverno moderado $\left(13,4^{\circ} \mathrm{C}\right.$ em média) com alguns dias mais rigorosos. A precipitação média anual é de 1.419,91 mm com um período de estiagem, não fixo, entre o outono e o inverno (INSTITUTO DE PESQUISA E PLANEJAMENTO URBANO DE CURITIBA, 2011).

Para o desenvolvimento desta pesquisa foram selecionadas tipologias de florestas urbanas mais frequentes nas cidades brasileiras, que são: Remanescente Florestal, Área Verde com Paisagismo e Arborização de Ruas. Estas três tipologias preestabelecidas foram divididas em cinco, devido às características do município. Isto porque na cidade de Curitiba, as áreas verdes com paisagismo e a própria arborização de ruas apresentam arranjos diferenciados entre si. Desta forma, as tipologias de floresta urbana adotadas nesta pesquisa foram:

a) Remanescente Florestal - considerada como toda área de cobertura arbórea composta por remanescente de Floresta com Araucária, pode estar localizada nos parques e bosques da cidade.

b) Área Verde Antiga - considerada como toda área de cobertura arbórea formada por agrupamentos de árvores implantadas com paisagismo Eclético, apresenta predomínio de árvores de grande porte e elevada quantidade de caminhos e pavimentação, podem ser considerados os parques e praças da cidade.

c) Área Verde Moderna - considerada como toda área de cobertura arbórea formada por agrupamentos de árvores implantadas com paisagismo Moderno, apresenta o predomínio de gramado sob as árvores, podem ser considerados os parques, praças e jardinetes da cidade.

d) Arborização de Rua - considerada como toda área de cobertura arbórea contínua composta por agrupamentos de árvores em plantio linear, acompanhando o sistema de ruas e avenidas.

e) Árvore isolada - considerada como a cobertura arbórea composta por um único indivíduo arbóreo, plantado no sistema viário de forma espaçada, não seguindo um padrão da cidade.

Para melhor caracterizar o ambiente urbano, a procura pelas áreas se restringiu à porção central da cidade, que melhor caracteriza o ambiente urbano consolidado. De modo a obter melhor representatividade das tipologias de floresta urbana, foram selecionadas três áreas para cada tipologia, totalizando assim 15 
locais de monitoramento, para essa seleção levou-se em consideração o tamanho e composição arbórea dos locais (Figura 1).

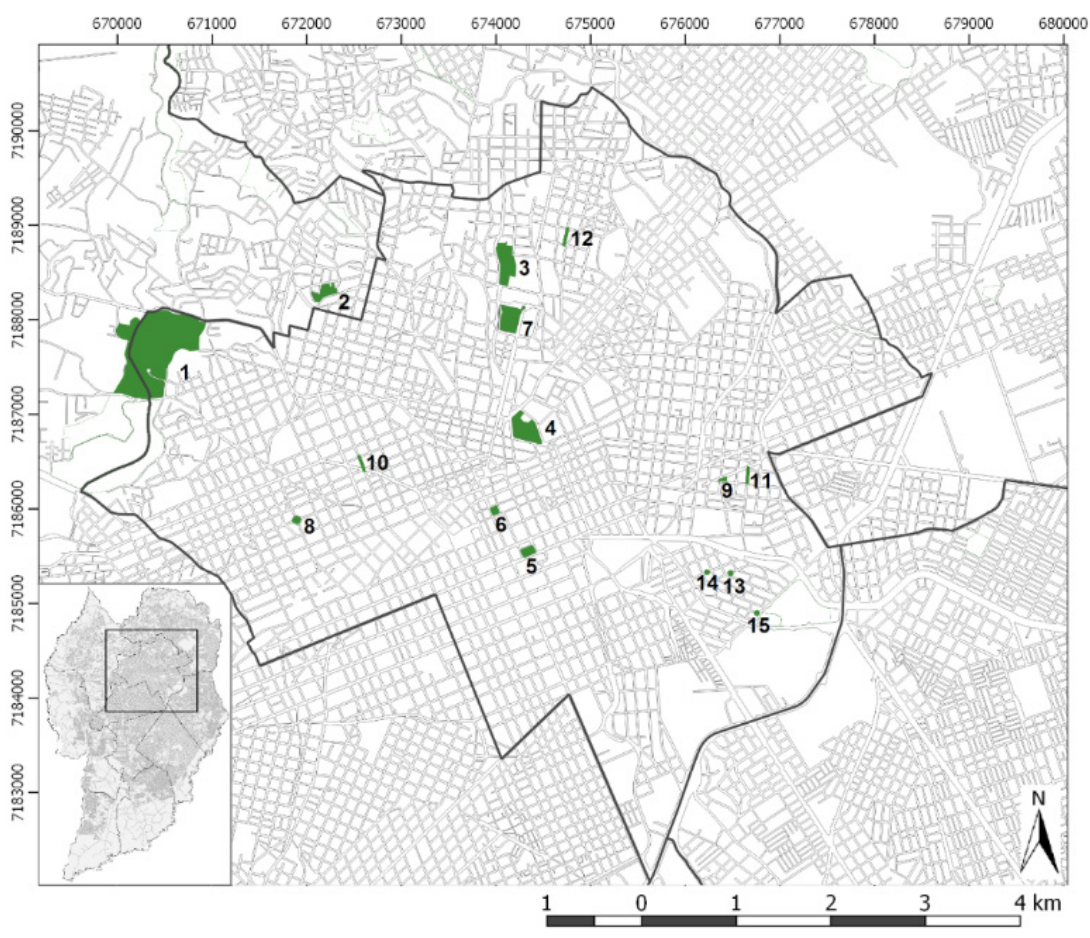

Em que: 1 = Parque Barigui; 2 = Bosque Gutierrez; 3 = Bosque João Paulo II; $4=$ Passeio Público; 5 = Praça Eufrásio Correia; 6 = Praça Carlos Gomes; $7=$ Praça Nossa Senhora de Salette; $8=$ Praça Alfredo Andersen; $9=$ Jardinete Henrique Knopholz; 10 = Rua Brigadeiro Franco; 11= Rua Ângelo Lopes; 12 = Rua Guaratuba; 13 = Lagerstroemia indica; 14 = Lafoensia pacari; 15 = Handroanthus chrysotrichus.

FIGURA 1: Locais selecionados para monitoramento microclimático na cidade de Curitiba-PR. FIGURE 1: Selected sites for microclimatic monitoring in the city of Curitiba-PR.

Análise da influência das tipologias no seu entorno imediato foi realizada com a coleta de dados por meio de transectos móveis, em cada uma das tipologias de floresta urbana selecionada: Remanescente Florestal - Parque Natural Municipal Barigui, Bosque Gutierrez e Bosque João Paulo II; Área Verde Antiga Passeio Público, Praça Eufrásio Correia e Praça Carlos Gomes; Área Verde Moderna - Praça Nossa Senhora de Salette, Praça Alfredo Andersen e Jardinete Henrique Knopholz; Arborização de Rua - R. Ângelo Lopes, R. Brigadeiro Franco e R. Guaratuba; Árvore isolada - Lagerstroemia indica (extremosa), Lafoensia pacari (dedaleiro) e Handroanthus chrysotrichus (ipê-amarelo-miúdo).

Este método consiste na coleta de informações meteorológicas a partir de equipamentos em movimento contínuo. Para isso, em cada tipologia de floresta urbana foi selecionada uma rua adjacente, que permitisse a realização de um percurso de $500 \mathrm{~m}$ de caminhamento. Buscou-se selecionar ruas com características semelhantes (referentes à largura da pista de rolamento, largura da calçada, composição dos canteiros e tipos de construção - até dois pavimentos) e no mesmo sentido geográfico (leste-oeste). Para a tipologia Arborização de Ruas, o sentido do caminhamento foi o mesmo do sentido da rua arborizada (nortesul), sendo que, para as árvores isoladas, a distância percorrida foi de $50 \mathrm{~m}$. Esta distância foi reduzida, devido à impossibilidade de garantir que outros elementos urbanos, além da árvore em questão, pudessem interferir nos dados meteorológicos (incluindo outras árvores) (Figura 2). 

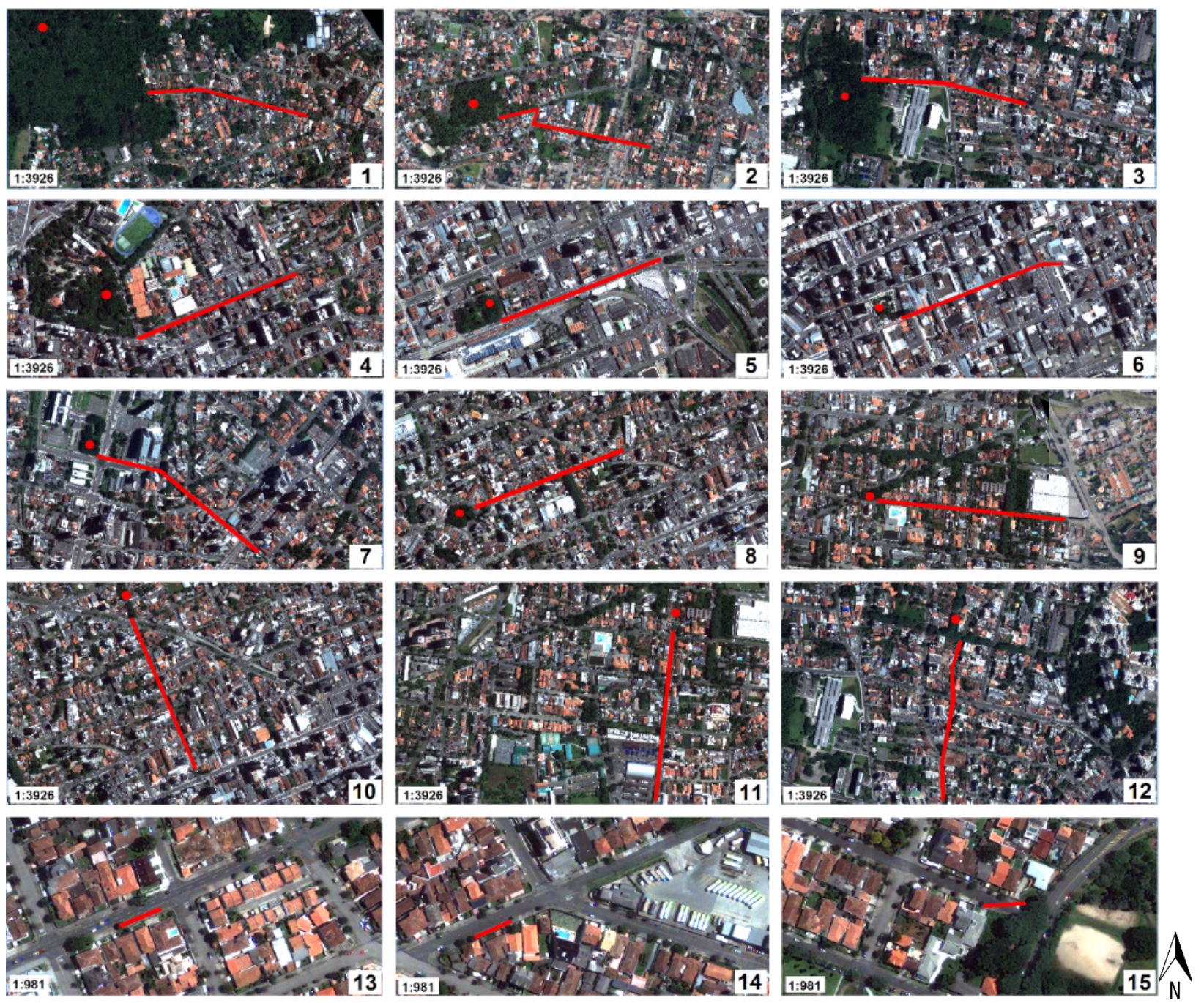

Em que: 1 = Parque Barigui, transecto na R. Alcides Munhoz; 2 = Bosque Gutierrez, transecto na R. Teffé; 3 = Bosque João Paulo II, transecto na R. Manoel Eufrásio; 4 = Passeio Público, transecto na R. Conselheiro Araújo; 5 = Praça Eufrásio Correia, transecto na Av. Sete de Setembro; 6 = Praça Carlos Gomes, transecto na R. Pedro Ivo; 7 = Praça Nossa Senhora de Salette, transecto na R. Ernani Santiago de Oliveira e R. Ivo Leão; 8 = Praça Alfredo Andersen, transecto na Al. Augusto Stellfeld; 9 = Jardinete Henrique Knopholz, transecto na R. Reinaldino S. de Quadros; $10=$ Rua Brigadeiro Franco, transecto na mesma rua; $11=$ Rua Ângelo Lopes, transecto na mesma rua; $12=$ Rua Guaratuba, transecto na R. São Pio X e R. Alberto Folloni; 13 = Lagerstroemia indica, transecto na R. Brasilio Itiberê; 14 = Lafoensia pacari, transecto na R. Sant'Ana; 15 = Handroanthus chrysotrichus, transecto na R. Cel João da Silva Sampaio.

FIGURA 2: Detalhamento do sentido das ruas selecionadas para caminhamento do transecto móvel em cada área. FIGURE 2: Detail of the direction of the selected streets for mobile transect walking in each area.

O trajeto do transecto móvel foi definido considerando-se que deveria ser percorrido em curto espaço de tempo, minimizando os efeitos das diferentes intensidades de radiação produzidas pela variação da altura aparente do sol, evitando a necessidade de correção dos dados de acordo com o período de medição (LEAL et al., 2011). Além disso, foi definido $500 \mathrm{~m}$ para evitar a interferência de mais elementos urbanos, incluindo outras formas de floresta urbana.

A influência das tipologias de floresta urbana no seu entorno imediato foi analisada em dias diferentes em função da disponibilidade de equipamentos. Desta forma, em cada dia, foram coletados os dados meteorológicos de uma das áreas selecionadas. Este procedimento foi repetido nas estações do verão (fevereiro e março) e inverno (julho e agosto). Os dias de coletas variaram conforme as condições 
climáticas do dia, pois havia a necessidade de céu limpo durante o horário de coleta dos dados, entre $12 \mathrm{e}$ $13 \mathrm{~h}$ (corrigido para 13 e 14h no horário de verão). Neste sentido, cabe destacar que as horas próximas ao meio-dia são as ocasiões ideais para discriminar entre os vários tipos de cobertura em pequenas distâncias (HUANG et al., 2008a).

Para a coleta de dados foram utilizadas duas miniestações da marca Kestrel ${ }^{\circledR}$, modelo 4200 , mantidas a uma altura aproximada de 1,50 m. Uma das miniestações permaneceu no centro da tipologia de floresta urbana e a outra foi utilizada no transecto móvel, este foi realizado a pé por um pesquisador. O percurso foi realizado na rua adjacente a área de estudo, com início na bordadura e término a 500 metros de distância, com a realização de quatro repetições.

Os dados meteorológicos foram coletados simultaneamente entre o equipamento localizado no interior da tipologia de floresta urbana e o equipamento utilizado no transecto móvel, uma vez que foram programados para coleta de informações a cada minuto. No percurso padronizou-se o mesmo ritmo de caminhada, sendo que a distância entre os pontos coletados foi de $50 \mathrm{~m}$. Em cada ponto (a cada $50 \mathrm{~m}$ ) foi feito uma pausa de 10 segundos antes da coleta dos dados meteorológicos, para estabilização dos dados. Estes procedimentos foram validados por Martini et al. (2014).

Todo o transecto móvel percorrido pelo pesquisador foi filmado, com o auxílio de uma câmera digital Sony Cyber-shot. O sentido do vento foi determinado no início de cada repetição, a partir da observação do movimento de uma fita acoplada às miniestações, tanto no equipamento que permaneceu estático no interior da área de estudo quanto no equipamento utilizado no transecto móvel.

Ao final das coletas de dados meteorológicos, todos os percursos realizados nas ruas adjacentes às áreas selecionadas foram caracterizados quanto à presença de vegetação, bem como estrutura urbana relevante para a pesquisa, como largura da pista de rolamento e calçada.

Os dados coletados por meio do método de transectos móveis permitiram analisar três variáveis: temperatura do $\operatorname{ar}\left({ }^{\circ} \mathrm{C}\right)$, umidade relativa do ar $(\%)$ e velocidade do vento $(\mathrm{m} / \mathrm{s})$. Com estes dados, foi possível analisar a influência das diferentes tipologias de floresta urbana no microclima do entorno imediato.

Os dados meteorológicos coletados a cada minuto no interior das tipologias de floresta urbana foram comparados estatisticamente com os valores obtidos nos respectivos trajetos percorridos, por meio do teste t de Student a 99\% de significância, para avaliar possíveis diferenças das condições meteorológicas. Esta análise foi realizada com a junção das informações do verão e inverno e também separadamente para cada estação.

\section{Equipamento meteorológico utilizado}

A miniestação Kestrel® 4200 Pocket Air Flow Tracker, da marca Nielsen Kellerman, utilizada nesta pesquisa, apresenta função Data Logger e registra até 3600 dados, em intervalos de 2 segundos a 12 horas. As variáveis medidas pelo aparelho são: velocidade do vento, temperatura do ar, umidade relativa do ar, razão de mistura, ponto de orvalho, temperatura do bulbo úmido, pressão atmosférica e altitude.

Conforme descrição do fabricante, o Kestrel apresenta precisão no valor da temperatura de $\pm 1^{\circ} \mathrm{C}$, abrangendo um intervalo de medição de -29 a $70^{\circ} \mathrm{C}$. Os valores de umidade relativa possuem precisão de \pm $3 \%$, abrangendo um intervalo de medição de 5 a $95 \%$ (sem condensação). A velocidade do vento apresenta uma precisão de $3 \%$ do valor de leitura, entre o intervalo de 0,6 a $40 \mathrm{~m} / \mathrm{s}$.

\section{RESULTADOS E DISCUSSÃO}

Os resultados da comparação entre o microclima do interior da área de monitoramento com o microclima do transecto percorrido mostraram diferenças estatísticas significativas entre o microclima interno e externo às tipologias de floresta urbana para a maioria das variáveis analisadas (Tabela 1). 
TABELA 1: Microclima no interior das tipologias de floresta urbana e no transecto móvel percorrido com análise estatística (teste $\mathrm{t}$ ).

TABLE 1: Microclimate in the interior of the urban forest types and in the mobile transmission percurred with statistical analysis (test $\mathrm{t}$ ).

\begin{tabular}{|c|c|c|c|c|c|c|c|c|c|}
\hline \multirow[t]{2}{*}{ Tipologias } & \multicolumn{3}{|c|}{ Temperatura $\left({ }^{\circ} \mathrm{C}\right)$} & \multicolumn{3}{|c|}{ Umidade relativa $(\%)$} & \multicolumn{3}{|c|}{ Velocidade do vento $(\mathrm{m} / \mathrm{s})$} \\
\hline & dentro & fora & test $\mathrm{t}$ & dentro & fora & test $\mathrm{t}$ & dentro & fora & test $\mathrm{t}$ \\
\hline \multicolumn{10}{|c|}{$\begin{array}{l}\text { Média das } \\
\text { estações }\end{array}$} \\
\hline $\begin{array}{c}\text { Remanescente } \\
\text { Florestal }\end{array}$ & 22,6 & 26,5 & $18,0 * *$ & 58,2 & 45,3 & $19,8^{* *}$ & 0,1 & 0,8 & $17,7^{* *}$ \\
\hline Área Verde Antiga & 24,7 & 26,8 & $16,0^{* *}$ & 41 & 39 & $3,0 * *$ & 0,8 & 0,9 & $0,3^{\text {ns }}$ \\
\hline Área Verde Moderna & 22,1 & 24 & $10,7 * *$ & 57,7 & 54,5 & $14,3 * *$ & 0,9 & 0,9 & $0,9^{\text {ns }}$ \\
\hline Arborização de Ruas & 22,8 & 24,6 & $13,5^{* *}$ & 52,1 & 50,6 & $2,7 * *$ & 0,7 & 1,1 & $7,1 * *$ \\
\hline Árvore Isolada & 22,3 & 24,4 & $13,6^{* *}$ & 49,8 & 46,5 & $8,4 * *$ & 1 & 0,8 & $1,8^{\mathrm{ns}}$ \\
\hline & \multicolumn{9}{|c|}{ Verão } \\
\hline $\begin{array}{c}\text { Remanescente } \\
\text { Florestal }\end{array}$ & 28,7 & 32,9 & $20,9 * *$ & 52,9 & 43,3 & $13,5^{* *}$ & 0,1 & 0,7 & $11,9 * *$ \\
\hline Área Verde Antiga & 29,8 & 32 & $11,7 * *$ & 39,7 & 37,1 & $2,7 * *$ & 0,8 & 0,9 & $1,7^{\mathrm{ns}}$ \\
\hline Área Verde Moderna & 26,3 & 28,3 & $16,2 * *$ & 58,3 & 54,6 & $5,9^{* *}$ & 1 & 1 & $0,1^{\text {ns }}$ \\
\hline Arborização de Ruas & 27,7 & 29,9 & $14,9 * *$ & 52,3 & 49,8 & $4,9 * *$ & 0,8 & 1,1 & $3,5^{* *}$ \\
\hline \multirow[t]{2}{*}{ Árvore Isolada } & 27,3 & 28,5 & $8,5^{* *}$ & 56,2 & 52,7 & $8,3 * *$ & 1,4 & 1,1 & $1,7^{\mathrm{ns}}$ \\
\hline & \multicolumn{9}{|c|}{ Inverno } \\
\hline $\begin{array}{c}\text { Remanescente } \\
\text { Florestal }\end{array}$ & 16,6 & 20 & $7,6 * *$ & 63,5 & 47,4 & $20,0^{* *}$ & 0 & 0,8 & $15,6^{* *}$ \\
\hline Área Verde Antiga & 19,5 & 21,6 & $6,9 * *$ & 42,3 & 41 & $2,0 *$ & 0,9 & 0,8 & $1,7^{\mathrm{ns}}$ \\
\hline Área Verde Moderna & 17,8 & 19,7 & $6,6 * *$ & 57,1 & 54,3 & $4,5 * *$ & 0,8 & 0,7 & $1,4^{\text {ns }}$ \\
\hline Arborização de Ruas & 17,9 & 19,3 & $7,5^{* *}$ & 52 & 51,5 & $0,6^{\mathrm{ns}}$ & 0,6 & 1,1 & $6,6^{* *}$ \\
\hline Árvore Isolada & 17,3 & 20,3 & $13,0^{* *}$ & 43,4 & 40,4 & $6,0 * *$ & 0,6 & 0,5 & $0,9^{\text {ns }}$ \\
\hline
\end{tabular}

Em que: (ns) não significativo; $(*)$ significativo a $5 \%$ de probabilidade; $(* *)$ significativo a $1 \%$ de probabilidade pelo teste $t$ de Student.

É possível observar, com a média das estações, que para as variáveis temperatura e umidade relativa houve diferença estatística entre os valores de dentro e fora da área de estudo para todas as tipologias de floresta urbana, sempre com menores valores de temperatura e maiores de umidade relativa no interior das áreas. A variável velocidade do vento foi estatisticamente distinta entre os registros dentro e fora no Remanescente Florestal e Arborização de Ruas, nas demais a diferença não foi significativa.

Outros estudos também demonstraram que as temperaturas do ar nos parques são tipicamente menores do que no ambiente urbano circundante (VANOS et al., 2012). Huang et al. (2008b) afirmam que as temperaturas sob a sombra das árvores apresentam-se estáveis na escala microclimática, enquanto os ambientes com presença de cimento (impermeabilização) são mais facilmente influenciados pelas condições de tempo, velocidade do vento e radiação solar.

Além disso, estes resultados também refletem o efeito do calor antropogênico proveniente da estrutura urbana, composta por superfície impermeável das edificações e revestimentos das ruas, que proporcionam diferenças termo-higrométricas significativas (LEAL; BIOND; BATISTA, 2014). 
Observa-se no interior do Remanescente Florestal que a temperatura foi $3,9^{\circ} \mathrm{C}$ menor do que no transecto percorrido, a umidade relativa foi maior em 12,9 unidades e a velocidade do vento $0,7 \mathrm{~m} / \mathrm{s}$ menor. $\mathrm{Na}$ Área Verde Antiga, a temperatura no interior foi $2,1^{\circ} \mathrm{C}$ menor, a umidade relativa foi maior em 2 unidades e a velocidade do vento $0,1 \mathrm{~m} / \mathrm{s}$ menor. Na Área Verde Moderna, a temperatura no interior foi $2,0^{\circ} \mathrm{C}$ menor, a umidade relativa foi maior em 3,2 unidades e a velocidade do vento foram iguais. Na Arborização de Ruas, a temperatura no interior foi $1,8^{\circ} \mathrm{C}$ menor, a umidade relativa foi maior em 1,5 unidades e a velocidade do vento $0,4 \mathrm{~m} / \mathrm{s}$ menor. Para os exemplares de Árvore Isolada, a temperatura no interior foi $2,1^{\circ} \mathrm{C}$ menor, a umidade relativa foi maior em 3,4 unidades e a velocidade do vento $0,2 \mathrm{~m} / \mathrm{s}$ maior.

A maior diferença de temperatura e umidade relativa foi observada no Remanescente Florestal, por se tratar de áreas com significativa quantidade de vegetação arbórea e presença de sub-bosque em vários estratos, desta forma, refere-se à tipologia com maior densidade de vegetação e superfície evapotranspirativa. O benefício microclimático proporcionado pela Área Verde Antiga foi semelhante ao da Área Verde Moderna, sendo menos expressivo do que no Remanescente Florestal. As Áreas Verdes diferenciam do Remanescente Florestal principalmente pela ausência de sub-bosque, que foi substituído por gramado ou área pavimentada e pela menor quantidade de espécies arbóreas.

$\mathrm{Na}$ sequência, observa-se que a Arborização de Ruas foi a tipologia que apresentou o menor benefício microclimático dentre todas as analisadas, inclusive foi menor do que a tipologia Árvore Isolada. Este resultado pode ter relação com a diferença de altura entre a copa das árvores, pois os exemplares de Árvore isolada apresentavam copa mais baixa do que os exemplares da Rua Arborizada. Desta forma, devido à superfície evapotranspirativa estar mais próxima da altura de coleta dos dados $(1,50 \mathrm{~m})$, o benefício microclimático pode ter sido mais acentuado. Ressalta-se ainda, que tanto a tipologia Árvore Isolada quanto a Arborização de Ruas foram as tipologias que apresentaram a maior taxa de impermeabilização no seu entorno.

A análise realizada separadamente para cada estação do ano mostrou essa mesma tendência, com diferenças estatísticas significativas entre o microclima interno e externo às tipologias para a maioria das variáveis analisadas.

Estes resultados permitem observar detalhadamente a ação de cada tipologia de floresta urbana nas diferentes estações do ano, enfatizando os detalhes que cada tipologia proporciona ao microclima, o que é importante segundo Cao et al. (2010). O autor afirma que os parques urbanos podem ajudar a mitigar os efeitos de ilha de calor urbano, no entanto, ainda não se sabe exatamente como as características desses parques podem afetar a formação de uma ilha de frescor.

Os dados demonstraram também, diferença estatística entre os valores de temperatura dentro e fora da área de estudo para todas as tipologias de floresta urbana, sempre com menores valores no interior das áreas. Para a umidade relativa também se verificou diferença estatística, exceto para a tipologia Arborização de Ruas na estação do inverno. A variável velocidade do vento foi estatisticamente distinta entre os registros dentro e fora na tipologia Remanescente Florestal e Arborização de Ruas, para ambas as estações do ano e nas demais a diferença não foi significativa.

No verão, a temperatura no interior do Remanescente Florestal foi $4,2^{\circ} \mathrm{C}$ menor do que no transecto percorrido, a umidade relativa foi maior em 9,6 unidades e a velocidade do vento $0,6 \mathrm{~m} / \mathrm{s}$ menor. Na Área Verde Antiga, a temperatura no interior foi $2,2^{\circ} \mathrm{C}$ menor, a umidade relativa foi maior em 2,7 unidades e a velocidade do vento $0,2 \mathrm{~m} / \mathrm{s}$ menor. Na Área Verde Moderna, a temperatura no interior foi $1,9^{\circ} \mathrm{C}$ menor, a umidade relativa foi maior em 3,6 unidades e a velocidade do vento foi igual. Na Arborização de Ruas, a temperatura no interior foi $2,3{ }^{\circ} \mathrm{C}$ menor, a umidade relativa foi maior em 2,6 unidades e a velocidade do vento $0,3 \mathrm{~m} / \mathrm{s}$ menor. Para os exemplares de Árvore Isolada, verificou-se que a temperatura no interior foi $1,2^{\circ} \mathrm{C}$ menor, a umidade relativa foi maior em 3,5 unidades e a velocidade do vento $0,2 \mathrm{~m} / \mathrm{s}$ maior.

No inverno, a temperatura no interior do Remanescente Florestal foi $3,5^{\circ} \mathrm{C}$ menor do que no transecto percorrido, a umidade relativa foi maior em 16,1 unidades e a velocidade do vento $0,8 \mathrm{~m} / \mathrm{s}$ menor. Na Área Verde Antiga, a temperatura no interior foi $2,1^{\circ} \mathrm{C}$ menor, a umidade relativa foi maior em 1,3 unidades e a velocidade do vento $0,1 \mathrm{~m} / \mathrm{s}$ maior. Na Área Verde Moderna, a temperatura no interior foi $1,8^{\circ} \mathrm{C}$ menor, a umidade relativa foi maior em 2,8 unidades e a velocidade do vento $0,1 \mathrm{~m} / \mathrm{s}$ maior. Na Arborização de Ruas, a temperatura no interior foi $1,5^{\circ} \mathrm{C}$ menor, a umidade relativa foi maior em 0,5 unidades e a velocidade do vento $0,5 \mathrm{~m} / \mathrm{s}$ menor. Para os exemplares de Árvore Isolada, verificou-se que a temperatura no interior foi 
$3,0^{\circ} \mathrm{C}$ menor, a umidade relativa foi maior em 3,0 unidades e a velocidade do vento $0,1 \mathrm{~m} / \mathrm{s}$ maior.

Assim, como na presente pesquisa, Andrade e Vieira (2007), em Lisboa (Portugal) também encontraram diferenças entre parques e os arredores construídos durante o verão.

No geral, pode-se afirmar que ao longo do transecto percorrido, a temperatura foi em média $2,3^{\circ} \mathrm{C}$ mais elevada do que no interior das tipologias de floresta urbana, a umidade relativa foi menor em 4,6 unidades e a velocidade do vento $0,2 \mathrm{~m} / \mathrm{s}$ maior, para as duas estações do ano. Esses resultados enfatizam o benefício microclimático proporcionado pelas florestas urbanas, em todas as suas formas (tipologias), mas ainda não é possível afirmar qual a sua influência na melhoria microclimática na parte externa dessas áreas.

Muitos autores já afirmaram que uma área com vegetação arbórea pode manter seu resfriamento interno e também beneficiar as áreas do entorno, pois o ar fresco pode se estender pelas ruas e edifícios da vizinhança, até uma determinada distância a favor do vento (SLATER, 2010; FRYD; PAULEIT; BUHLER, 2011; LIN et al., 2015). Contribuindo de maneira eficaz na redução das temperaturas mais altas geradas pela ilha de calor urbano (BOWLER et al., 2010; UNGER; SAVIC; GAL, 2011).

Ainda são poucos os estudos que quantificam essa ação por meio de coletas de dados pontuais para entender de que modo isso acontece, pois os fatores que proporcionam o frescor no entorno de um parque podem não ser os mesmos que determinam o frescor no interior das áreas (CHANG; LI, 2014). Além disso, embora alguns resultados de pesquisas sugiram que o efeito de resfriamento das áreas verdes possa se estender até as áreas do entorno e melhorar o ambiente térmico, a extensão desse benefício também depende de outros fatores, como a topografia, as estruturas adjacentes e as condições do vento (FRYD; PAULEIT; BUHLER, 2011).

\section{CONCLUSÕES}

As diferentes tipologias de floresta urbana exercem influência significativa no microclima. Foram encontradas diferenças estatísticas entre o microclima interno e externo as tipologias de floresta urbana, para as variáveis temperatura e umidade relativa do ar.

Ao longo do transecto percorrido, a temperatura foi em média $2,3{ }^{\circ} \mathrm{C}$ mais elevada do que no interior das tipologias de floresta urbana, a umidade relativa foi menor em 4,6 unidades e a velocidade do vento 0,2 $\mathrm{m} / \mathrm{s}$ maior.

A maior diferença de temperatura e umidade relativa entre o ambiente interno e externo foi encontrada no Remanescente Florestal $\left(3,9^{\circ} \mathrm{C}\right.$ e 12,9 unidades), possivelmente devido à área apresentar maior densidade de vegetação e superfície evapotranspirativa do que as demais. Já a menor diferença foi observada na Arborização de Ruas $\left(1,8^{\circ} \mathrm{C}\right.$ e 1,5 unidades) com variação nas estações do ano, tipologia, com maior taxa de impermeabilidade e menor quantidade de superfície evapotranspirativa próxima à altura de coleta dos dados.

\section{AGRADECIMENTOS}

À Fundação Araucária de Apoio ao Desenvolvimento Científico e Tecnológico do Paraná pelo financiamento à compra dos equipamentos.

\section{REFERÊNCIAS}

ALVAREZ, I. A. Qualidade do espaço verde urbano: uma proposta de índice de avaliação. 2004. 187 f. Tese (Doutorado em Agronomia) - Escola Superior de Agricultura Luiz de Queiroz, Universidade de São Paulo, Piracicaba, 2004.

ANDRADE, H.; VIEIRA, R. A climatic study of an urban green space: the Gulbenkian Park in Lisbon (Portugal). Finisterra, Lisboa, v. 42, n. 84, p. 27-46, 2007.

ARAÚJO, M. N.; ARAÚJO, A. J. Série de cadernos técnicos da agenda parlamentar: arborização urbana. Curitiba: CREA-PR, 2011.

ARMSON, D.; STRINGER, P.; ENNOS, A. R. The effect of tree shade and grass on surface and globe temperatures in an urban area. Urban Forestry \& Urban Greening, Amsterdam, v. 11, p. 245-255, 2012. 
BARBIRATO, G. M.; TORRES, S. C.; SOUZA, L. C. L. Clima urbano e eficiência energética nas edificações. Rio de Janeiro: PROCEL EDIFICA, 2011.

BASSO, J. M.; CORRÊA, R. S. Arborização urbana e qualificação da paisagem. Paisagem e Ambiente, São Paulo, n. 34, p. 129-148, 2014.

BIONDI, D. Floresta urbana: conceitos e terminologias. In: Floresta urbana. Curitiba: A autora, 2015. p. 11-27.

BOWLER, D. E. et al. Urban greening to cool towns and cities: A systematic review of the empirical evidence. Landscape and Urban Planning, Amsterdam, v. 97, p. 147-155, 2010.

BROWN, R. D. et al. Designing urban parks that ameliorate the effects of climate change. Landscape and Urban Planning, Amsterdam, v. 138, p. 118-131, 2015.

CAO, X. et al. Quantifying the cool island intensity of urban parks using ASTER and IKONOS data. Landscape and Urban Planning, Amsterdam, v. 96, p. 224-231, 2010.

CHANG, C.; LI, M. Effects of urban parks on the local urban thermal environment. Urban Forestry \& Urban Greening, Amsterdam, v. 13, p. 672-681, 2014.

CHANG, C.; LI, M.; CHANG, S. A preliminary study on the local cool-island intensity of Taipei city parks. Landscape and Urban Planning, Amsterdam, v. 80, p. 386-395, 2007.

CHEN, A. et al. Effect of urban green patterns on surface urban cool islands and its seasonal variations. Urban Forestry \& Urban Greening, Amsterdam, v. 13, p. 646-654, 2014.

DRAPER, D. B.; RICHARDS, P. A. Dictionary for managing trees in urban environments. Collinwood: CSIRO, 2009.

FRYD, O.; PAULEIT, S.; BUHLER, O. The role of urban green space and trees in relation to climate change. CAB Reviews, Wallingford, v. 6, n. 53, p. 1-14, 2011.

HAMADA, S.; OHTA, T. Seasonal variations in the cooling effect of urban green areas on surrounding urban areas. Urban Forestry \& Urban Greening, Amsterdam, v. 9, p. 15-24, 2010.

HUANG, L. et al. A fieldwork study on the diurnal changes of urban microclimate in four types of ground cover and urban heat island of Nanjing, China. Building and Environment, Oxford, v. 43, p. 7-17, 2008 a. HUANG, L. et al. Scale impacts of land cover and vegetation corridors on urban thermal behavior in Nanjing, China. Theorethical and Applied Climatology, Hamburg, v. 94, p. 241-257, 2008b.

INSTITUTO DE PESQUISA E PLANEJAMENTO URBANO DE CURITIBA. Desenvolvimento sustentável: indicadores de sustentabilidade de Curitiba - 2010. Curitiba: IPPUC, 2011.

JIANG, B. et al. A dose-response curve describing the relationship between tree cover density and landscape preference. Landscape and Urban Planning, Amsterdam, v. 139, p. 16-25, 2015.

JOYE, Y.; BERG, A. V. D. Is love for green in our genes? A critical analysis of evolutionary assumptions in restorative environments research. Urban Forestry \& Urban Greening, Amsterdam, v. 10, n. 4, p. 261-268, 2011.

KONG, F. et al. A satellite image-based analysis of factors contributing to the green-space cool island intensity on a city scale. Urban Forestry \& Urban Greening, Amsterdam, v. 13, p. 846-853, 2014.

KURBÁN, A. et al. Aporte de la forestación al control del clima urbano en zona árida. Avances en Energías Renovables y Medio Ambiente, Salta, v. 6, n. 1, p. 43-48, 2002.

LEAL, L. A influência da vegetação no clima urbano da cidade de Curitiba - PR. 2012. 172 f. Tese (Doutorado em Engenharia Florestal) - Universidade Federal do Paraná, Curitiba, 2012.

LEAL, L. et al. Levantamento meteorológico expedito para análise da influência microclimática do Bosque Estadual João Paulo II, Curitiba - PR. In: ENCONTRO SUL-BRASILEIRO DE METEOROLOGIA, 4., 2011, Pelotas. Anais... Pelotas: SBMET, 2011. p. 1-9.

LEAL, L.; BIOND, D.; BATISTA, A. C. Influência das florestas urbanas na variação termo-higrométrica da área intraurbana de Curitiba - PR. Ciência Florestal, Santa Maria, v. 24, n. 4, p. 807-820, 2014.

LIN, W. et al. Calculating cooling extents of green parks using remote sensing: Method and test. Landscape and Urban Planning, Amsterdam, v. 134, p. 66-75, 2015.

MARTINI, A. et al. Microclima e conforto térmico de um fragmento florestal na cidade de Curitiba - PR, Brasil. In: CONGRESO FORESTAL LATINOAMERICANO, 5., 2011, Lima. Anais... Lima: [s. n.], 2011. MARTINI, A. Microclima e conforto térmico proporcionado pelas árvores de rua na cidade de Curitiba- PR. 2013. 129 f. Dissertação (Mestrado em Engenharia Florestal) - Universidade Federal do 
Paraná, Curitiba, 2013.

MARTINI, A. et al. Validação da metodologia de transéctos móveis para coleta de dados microclimáticos no ambiente urbano. In: SIMPÓSIO BRASILEIRO DE CLIMATOLOGIA GEOGRÁFICA, 11., 2014, Curitiba. Anais... Curitiba: ABCLIMA, 2014.

ODUM, E. P. Fundamentos de ecologia. 7.ed. São Cengage: Learning, 2004.

RASKOVI, S.; DECKER, R. The influence of trees on the perception of urban squares. Urban Forestry \& Urban Greening, Amsterdam, v. 14, p. 237-245, 2015.

SHASHUA-BAR, L. et al. Microclimate modelling of street tree species effects within the varied urban morphology in the Mediterranean city of Tel Aviv, Israel. International Journal of Climatology, Reading, v. 30, p. 44-57, 2010.

SHASHUA-BAR, L.; PEARLMUTTER, D.; ERELL, E. The cooling efficiency of urban landscape strategies in a hot dry climate. Landscape and Urban Planning, Amsterdam, v. 92, p. 179-186, 2009.

SLATER, G. The cooling ability of urban parks. 2010. $141 \mathrm{f}$. Thesis (Natural Sciences and Engineering Research) - School of Environmental and Rural Design, University of Guelph, Guelph, 2010.

STREILING, S.; MATZARAKIS, A. Influence of single and small clusters of trees on the bioclimate of a city: a case study. Journal of Arboriculture, Champaign, v. 29, n. 6, p. 309-316, 2003.

UNGER, J.; SAVIC, S.; GAL, T. Modelling of the annual mean urban heat island. pattern for planning of representative urban climate station network. Advances in Meteorology, Cairo, v. 2011, p. 1-9, 2011.

VANOS, J. K. et al. Human energy budget modeling in urban parks in Toronto, ON, and applications to emergency heat stress preparedness. Journal of Applied Meteorology and Climatology, Washington, v. 51, n. 9 , p. 1639-1653, 2012. 